\title{
Postsynaptic dopamine receptor stimulation and sensorimotor behavior in rats with a unilateral medial forebrain bundle lesion
}

\author{
D. C. UGURU-OKORIE \\ University of Ibadan, Ibadan, Nigeria
}

\begin{abstract}
This study was designed essentially to compare the effects of ip injections of apomorphine, a direct-acting postsynaptic-dopamine-receptor-stimulating agent, on forepaw use and rotational behavior in rats with a unilateral MFB lesion. Apomorphine $(0.05 \mathrm{mg} / \mathrm{kg})$ reversed the ipsiversive circling behavior of all lesioned rats, but failed to restore the use of the preoperatively preferred forepaw in the contralaterally lesioned group. It is proposed that rotational behavior and forelimb use are governed, on different principles, by the DA systems of the brain.
\end{abstract}

In experimental animals, akinesia, defined as the inability to initiate voluntary movements, is known to result from bilateral lesions that interrupt the medial forebrain bundle (Harrison, 1940; Mettler, 1945; Nauta, 1946; Ranson, 1939; Ungerstedt, 1971a).

Also, rats with a relatively discrete (6-hydroxydopamine induced) degeneration of the nigrostriatal DA system (Ungerstedt, 1968, 1971b), a pathway that carries most of the forebrain's supply of this amine (Carlsson, 1959; Bertler and Rosengren, 1959), develop a supersensitivity to DA agonists in the denervated neostriatum (Ungerstedt, 1971c). Apomorphine, a direct-acting DA-receptor-stimulating agent (Anden, Rubenson, Fuxe, \& Hokfelt, 1967; Ernst, 1967), or L-dopa, a DA precursor (Hornykiewicz, 1966), therefore, causes unilaterally 6-hydroxydopamine-lesioned animals to rotate toward the intact side (Ungerstedt, 1971c).

More recent experiments have shown that a unilateral 6-hydroxydopamine lesion of the nigrostriatal dopamine system causes rats to reverse their forepaw preference if they sustain such damage on the side contralateral to the preoperatively preferred forepaw (Uguru-Okorie \& Arbuthnott, 1981) and to rotate more or less exclusively towards the lesion side (Uguru-Okorie, 1982).

The aim of the present study was to test the hypothesis that sensorimotor functioning and rota-

This study was conducted in the laboratories of the M.R.C. Brain Metabolism Unit, Edinburgh. The author wishes to acknowledge with deep gratitude the immense help received during the study from Prof. David M. Vowles, Head of the Department of Psychology, University of Edinburgh, from Dr. Gordon W. Arbuthnott of the M.R.C. Brain Metabolism Unit, Edinburgh, and from their two departments. Prof. Vowles's constant encouragement throughout the study is especially appreciated. Many thanks are also extended to Mrs. Anne Aderogba of the Department of Geography, University of Ibadan, for kindly preparing the figure. The author's mailing address is: Department of Psychology, University of Ibadan, Ibadan, Nigeria. tional behavior are governed by brain dopamine on the same principles.

\section{METHOD}

\section{Subjects}

The subjects were 21 male Wistar albino rats weighing 175 $200 \mathrm{~g}$ at the time of surgery. Throughout the study, the animals were housed in pairs in plastic cages (measuring $56 \times 38 \times 18 \mathrm{~cm}$ ) in reverse daylight.

\section{Behavioral Studies}

A pilot study had shown that apomorphine can, at a dose of $0.05 \mathrm{mg} / \mathrm{kg}$, produce contraversive circling in a hungry rat with a unilateral 6-hydroxydopamine lesion of the medial forebrain bundle and still allow the animal to work for food reward on a continuous reinforcement schedule when tested in a Skinner box 2 months after surgery.

Following a 7-day disturbance-free orientation period in the laboratory housing condition, the rats were deprived of food for $48 \mathrm{~h}$ and then trained to press a lever for food in a two-lever operant behavior box. They were free to operate either lever, and were observed to have a certain amount of preference for a particular forepaw as reflected in the number of food-rewarded leverpresses executed with each paw. They received a single 45-mg food pellet (Campden Instruments) for every lever depression.

After training, the subjects were given two 25 -min sessions in the box on consecutive days. Then they underwent surgery. They were tested, without further treatment, on Days 8 and 9 after surgery and on 2 consecutive days 8 weeks later. Seven days thereafter, each rat was given an injection of apomorphine $(0.05 \mathrm{mg} / \mathrm{kg}$ in $1 \mathrm{ml} / \mathrm{kg}$ isotonic saline, ip) and tested in a single 25 -min session in the box. A final 25-min session was given 1 week after that, following an injection of isotonic saline $(1 \mathrm{ml} / \mathrm{kg}$, ip). Data from the last of the preapomorphine testing sessions were used as baseline data ("No treatment" columns in Figure 1) for assessing the effects of apomorphine on the behavior investigated.

\section{Surgery}

The animals were pretreated for $30 \mathrm{~min}$ with $50 \mathrm{mg} / \mathrm{kg}$ pargyline and $25 \mathrm{mg} / \mathrm{kg}$ desmethylimipramine, anesthetized with fluothane, and then injected with either 6-OHDA ( $8 \mu \mathrm{g}$ of the base in $4 \mu \mathrm{l}$ ) or vehicle $(2 \mu \mathrm{g} \mathrm{L}$-ascorbic acid in $4 \mu \mathrm{l})$ over an 8 -min period, using the following coordinates: $4.1 \mathrm{~mm}$ behind the bregma, $1.1 \mathrm{~mm}$ lateral to midline, $7.6 \mathrm{~mm}$ below the cortical surface. Subjects were randomly assigned to one of three surgical groups. Group 1 received 6-OHDA in the MFB of the hemisphere contralateral 
to the preferred paw (eight successfully lesioned rats); Group 2 rats were injected ipsilateral to the preferred paw (seven successful operations); Group 3 rats were injected with vehicle either ipsilateral or contralateral to the preferred paw (three of each).

\section{Verification of Lesion}

The subjects were sacrificed 12 weeks after surgery by quick stunning followed by cervical dislocation. The brains were removed rapidly and cooled in saline at $0^{\circ} \mathrm{C}$. A coronal knifecut was made through the brain at the level of the optic chiasma. Then the septal area was cut away from the anterior piece of brain tissue, and the two striatal samples were picked out.

The rest of the anterior piece of brain tissue was separated down the midline to form two "mesolimbic" samples (comprising mainly the olfactory tubercle, nucleus accumbens, and frontal cortex). All samples were stored in liquid nitrogen until assayed for dopamine and norepinephrine by a modification of the method of Coyle and Henry (1973) and Palkovitz, Brownstein, Saavedra, and Axelrod (1974).

\section{RESULTS}

Statistical analysis of the data graphically presented in Figure 1 revealed a significant difference between preferred and nonpreferred paws in all three groups prior to surgery $(\mathrm{p}=.01$ for the two lesion groups, and $\mathrm{p}=.025$ for the vehicle-injected group, Wilcoxon matched pairs signed-ranks test, one-tailed). Full rotations were roughly the same in either direction in all three groups. After surgery, the "contralateral"' group, but not the other two groups, significantly reversed their forepaw preferences $(p=.025$ at the 1 -week postoperative test and $p=.01$ at the 8-week postoperative test, Wilcoxon test, one-tailed). As the figure shows, surgery did not substantially increase rotation toward either direction in the control group, but did significantly enhance ipsiversive rotations at the expense of contraversive rotations in the lesion groups at the two preapomorphine tests $(p=.005$, for the "contralateral" group, and $p=.01$, for the "ipsilateral" group, Wilcoxon test, onetailed).

The control group did not display substantial postoperative loss of catecholamines in the brain regions sampled, but all lesioned subjects did sustain severe

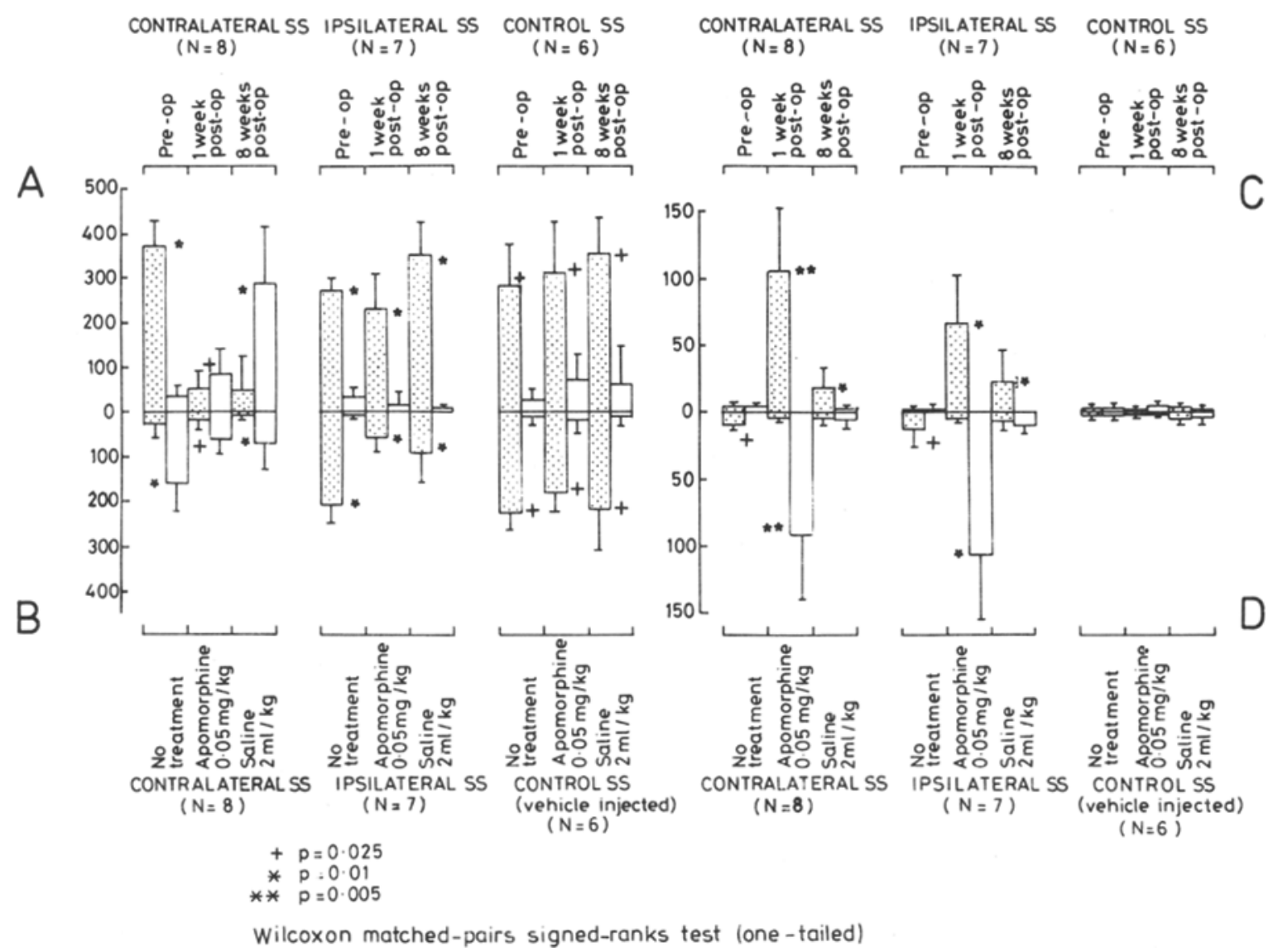

Figure 1. Mean forepaw preference $(A, B)$ and complete rotations to each side $(C, D)$ displayed by contralaterally lesioned, ipsilaterally lesioned, and vehicle-injected groups of rats in two 25 -min sessions of testing before surgery, 1 week after surgery, and 8 weeks after surgery (upward plotted data), and during 25 min of testing without treatment, following apomorphine treatment, and following saline treatment (downward plotted data). Each column represents the mean number of effective leverpresses executed with the preoperatively preferred (dotted columns) or nonpreferred (open columns) forepaw, or the mean number of rotations toward the injected hemisphere (dotted columns) or away from it (open columns). Each bar represents 1 SD. 
Table 1

Mean and SD of Percentage of Catecholamine Reductions in the Injected Hemisphere of 6-Hydroxydopamine-Lesioned and Control Rats

\begin{tabular}{|c|c|c|c|c|c|c|c|c|c|}
\hline \multirow[b]{3}{*}{ Subject Groups } & \multirow[b]{3}{*}{$\mathrm{N}$} & \multicolumn{4}{|c|}{ Dopamine } & \multicolumn{4}{|c|}{ Norepinephrine } \\
\hline & & \multicolumn{2}{|c|}{ Striatal } & \multicolumn{2}{|c|}{ Mesolimbic } & \multicolumn{2}{|c|}{ Striatal } & \multicolumn{2}{|c|}{ Mesolimbic } \\
\hline & & Mean & SD & Mean & SD & Mean & SD & Mean & $\mathrm{SD}$ \\
\hline Contralaterally Lesioned Group* & 8 & 99 & 2 & 94 & 10 & 90 & 9 & 34 & 26 \\
\hline Ipsilaterally Lesioned Group* & 7 & 98 & 2 & 94 & 8 & 81 & 12 & 35 & 37 \\
\hline Vehicle-Injected Group** & 6 & 6 & 12 & 8 & 9 & 14 & 31 & 1 & 3 \\
\hline
\end{tabular}

*Experimental group. $\quad{ }^{* *}$ Control group.

reductions of dopamine in the striatal and mesolimbic areas and of norepinephrine in the striatal area (Table 1). Apomorphine and saline treatments did not affect rotational behavior or forepaw use in the control group. Apomorphine did, however, significantly reverse the postoperative direction of rotation in the lesion groups $(\mathrm{p}=.005$, for the "contralateral" group, and $p=.01$, for the ipsilateral group, Wilcoxon test, one-tailed). The postoperative patterns of forepaw use were unaffected by apomorphine or saline in any of the groups.

\section{DISCUSSION}

The main finding of the present study is that although stimulation of dopaminergic postsynaptic receptors, through ip apomorphine injections, reverses the direction of rotation produced by a unilateral M.F.B. lesion, this treatment fails to reverse lesion-induced paw preferences. The observed effect of apomorphine on circling behavior is in agreement with previous reports (Fuxe \& Ungerstedt, 1976; Ungerstedt, 1971c) and supports the view that both the pre- and posttreatment "preferred" directions of rotation in these animals were determined by relative activities on the postsynaptic dopamine receptor sites of the two hemispheres. The failure of apomorphine to restore the preoperative forepaw preference in lesioned rats appears to suggest, on the other hand, that forepaw preference in these animals is not simply a matter of relative activities on the dopaminergic postsynaptic receptors of the two hemispheres. However, it is difficult to be sure of this, unless at least the drug dose is varied, since it is conceivable that rotational behavior and forepaw use may be functions that require different levels of central dopamine receptor stimulation. Further work has been designed to tackle this question.

\section{REFERENCES}

Anden, N.-E., Rubenson, A., Fuxe, K., \& Hokfelt, T. (1967). Evidence for dopamine receptor stimulation by apomorphine. Journal of Pharmacy and Pharmacology, 19, 627-629.

Bertler, A., \& Rosengren, E. (1959). Occurrence and distribution of catecholamines in brain. Acta Physiologica Scandinavica Supplementum, 47, 350-361.
Carlsson, A. (1959). The occurrence, distribution and physiological role of catecholamines in the nervous system. Pharmacological Review, 11, 490-493.

Coyle, J. T., \& Henry, D. (1973). Catecholamines in fetal and newborn rat brain. Journal of Neurochemistry, 21, 61-67.

ErNst, A. M. (1967). Mode of action of apomorphine and dextroamphetamine on gnawing compulsion in rats. Psychopharmacologia, 10, 310-323.

FuXe, K., \& UNGERSTEDT, U. (1976). Anti-parkinsonian drugs and dopaminergic neostriatal mechanisms: Studies in rats with unilateral 6-hydroxydopamine (6-OHDA)-induced degeneration of nigrostriatal DA pathway and quantitative recording of rotational behaviour. Pharmacological Therapeutics Bulletin, 2, 41-47.

Harrison, F. (1940). An attempt to produce sleep by diencephalic stimulation. Journal of Neurophysiology, 3, 156-165.

HoRNYKIEWICz, O. (1966). Dopamine (3-hydroxytryptamine) and brain function. Pharmacological Review, 18, 925-964.

MetTlen, F. A. (1945). Effects of bilateral simultaneous subcortical lesions in the primate. Journal of Neuropathology and Experimental Neurology, 4, 99-122.

NaUTA, W. J. H. (1946). Hypothalamic regulation of sleep in rats: An experimental study. Journal of Neurophysiology, 9, 285-316.

Palkovitz, M., Brownstein, M., Sanvedha, J. M., \& Axelrod, J. (1974). Norepinephrine and dopamine content of hypothalamic nuclei of the rat. Brain Research, 77, 137-149.

Ranson, S. W. (1939). Somnolence caused by hypothalamic lesions in the monkey. Archives of neurology and psychiatry, 41, 1-23.

Uguru-OKonIE, D. C. (1982). Nigrostriatal dopaminergic control of operant and spatial behavior in the rat. Physiological Psychology, 10, 97-107.

Uguru-Okorie, D. C., \& Arbuthnott, G. W. (1981). Altered paw preference after unilateral 6-hydroxy-dopamine injections into lateral hypothalamus. Neuropsychologia, 19, 463-467.

UNGERSTEDT, U. (1968). 6-hydroxydopamine induced degeneration of central monoamine neurons. European Journal of Pharmacology, 5, 107-110.

UNGERSTEDT, U. (1971a). Adipsia and aphagia after 6-hydroxydopamine induced degeneration of the nigrostriatal dopamine system in the rat brain. Acta Physiologica Scandinavica, 367 (Suppl.), 95-122.

UNGERSTEDT, U. (1971b). Histochemical studies on the effects of intracerebral and intraventricular injections of 6-hydroxydopamine on monoamine neurons in the rat brain. In T. Malmfors \& H. Thoenen (Eds.), 6-hydroxydopamine and catecholamine neurons. Amsterdam: North-Holland.

Ungerstedt, U. (1971c). Postsynaptic supersensitivity after 6-hydroxydopamine induced degeneration of the nigrostriatal dopamine system. Acta Physiologica Scandinavica, 367(Suppl.), 69-93.

(Manuscript received April 11, 1983; revision accepted for publication December 7, 1983.) 